\title{
Dairy cow behaviour around calving: Its relationship with management practices and environmental conditions
}

\author{
Fabiola Matamala ${ }^{\mathrm{a}}$, Ana Strappini ${ }^{\mathrm{b}}$, Pilar Sepúlveda-Varas ${ }^{\mathrm{c}^{*}}$
}

\begin{abstract}
Calving is one of the most challenging and painful experiences for dairy cattle and a process that involves coping with physical and physiological changes, as well as environmental and management-related stressors. In recent years, it has been argued that the application of cow behaviour knowledge might facilitate their efficacious management during calving. This review aims to summarise and discuss current knowledge regarding the behavioural changes that occur around calving time. The relationship between calving behaviour, management practices, and environmental conditions in dairy cattle raised in intensive indoor production systems, as well as pasture-based systems, is also discussed. First, we briefly outline the process of parturition and the concept of maternal behaviour. We then describe behavioural changes that occur around parturition in normal and dystocic births and how variations in these behaviours can be used to predict normal or assisted calving in dairy cattle; particular emphasis is placed on the role of feeding, rumination, and lying behaviour. Finally, we review how management practices and environmental conditions can influence cow's behaviour at calving and discuss the importance of providing an environment that accommodates the behaviour they are motivated to perform. This review presents evidence that the time a cow is moved to the calving area, the type of group housing and the provision of a secluded area to calve, can impact the behavioral responses of dairy cows at calving. Evidence regarding the effects of exposure to environmental conditions such as heat during summer, and/or cold, wet and mud during winter can also have a negative impact on behaviour, suggesting potential benefits of providing cows with a protected area to calve. We conclude that a better understanding of the behaviour of parturient cows may help producers improve the care and management around calving time.

Key words: cattle, parturition, welfare, pasture.
\end{abstract}

\section{INTRODUCTION}

Calving is defined as the process of giving birth and, as in other mammals, it is a painful and stressful event for dairy cows (Maineau and Manteca 2011). Prolonged calving, delayed parturition, or severe assisted extraction of the calf at birth can result in a difficult birth, also called dystocia (Mee 2004). Research has shown the negative effect of calving difficulty on health, behaviour, and performance of dairy cows and higher neonatal mortality and morbidity in their calves (Mee 2008, Schuenemann et al 2011, Barrier et al 2013). In consequence, ensuring smooth parturition might be beneficial for the welfare of the cow and its calf.

The observation of behavioural changes is widely used to predict the onset of calving in dairy cows (Miedema

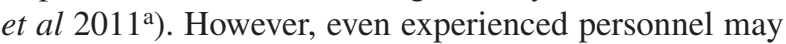
fail to detect calving time since perceptible behavioural changes do not occur for every cow or at a consistent time across calving (Ouellet et al 2016, Lange and Heuwieser 2017). Due to the current availability of technologies that

Received: 17.12.2019.

Accepted: 11.05.2020.

aPrograma de Doctorado, Escuela de Graduados, Facultad de Ciencias Veterinarias, Universidad Austral de Chile, Valdivia, Chile.

bInstituto de Ciencia Animal, Facultad de Ciencias Veterinarias, Universidad Austral de Chile, Valdivia, Chile.

'Instituto de Ciencias Clínicas Veterinarias, Facultad de Ciencias Veterinarias, Universidad Austral de Chile, Valdivia, Chile.

*Corresponding author: P Sepúlveda-Varas; Casilla PO BOX 567, Chile; pilar.sepulveda@uach.cl facilitate behaviour monitoring, in recent years researchers have shown increased interest in the assessment of calving behaviour for predicting calving time (Ouellet et al 2016, Borchers et al 2017). Such sort of calving detection can be advantageous to ensure the provision of adequate supervision, timely human intervention (when difficulty arises), and early care to the newborn calf (Barrier et al 2012).

Understanding the behaviour of cows around the time of calving can improve the care and management (von Keyserlingk and Weary 2007) and helps to design facilities that meet the behavioural needs of the animals (Cook and Nordlund 2004). In the last 10 years, there has been a growing body of literature investigating the design and management of an appropriate calving site when provided in an indoor calving facility (i.e. Proudfoot et al 2014, Rørvang et al 2017 ${ }^{\mathrm{a}}, 2018^{\mathrm{a}}$ ). However, limited research on this subject has been carried out in grazing systems where other considerations may need to be accounted for; for example, in seasonal-calving grazing systems the calving season is often associated with periods of inclement weather (i.e. cold, wet, and muddy conditions) during winter and early spring (Tucker et al 2007).

The aim of this review is to summarise and discuss current knowledge regarding the behavioural changes that occur around calving time. The relationship between calving behaviour, management practices, and environmental conditions in dairy cattle raised in both intensive indoor production and pasture-based systems is also discussed. First, we briefly outline the process of parturition and the concept of maternal behaviour. Secondly, we describe behavioural changes that occur around parturition in normal and dystocic births, and how variations in these behaviours 
can be used to predict normal or assisted calving in dairy cattle; particular emphasis is placed on the role of feeding, rumination and lying behaviour. Finally, we review how management practices and environmental conditions can influence the cow's behaviour at calving and discuss the importance of providing an environment that accommodates the behaviour they are motivated to perform.

\section{PARTURITION PROCESS}

Parturition is defined as the process of delivering a fully-grown foetus upon completion of the normal pregnancy period. In dairy cattle, the length of gestation ranges from 277 to $287 \mathrm{~d}$ depending on the breed, parity, twinning, and sex of the calf. For instance, in Holstein heifers and cows, gestation length averaged 278 and 279 d, respectively (Norman et al 2009). The process of parturition is traditionally divided into three phases, referred to as the stages of parturition, that move from one stage to the next (Wehrend et al 2006, Miedema et al 2011 b, Schuenemann et al 2011), ending with the delivery of the calf and the expulsion of the placenta (Noakes 2001, Schuenemann et al 2011).

The first stage, or dilation phase, comprises the dilation of the soft tissues of the birth canal (including the ligaments of the pelvis, cervix, and vulva), the onset of myometrial contractions, and the rotation of the fetus to its birthing position and its movement to the birth canal (Noakes 2001). It has been reported that this stage may be initiated as early as $24 \mathrm{~h}$ before the expulsion of the calf, but variation exists among cows (Jackson 2004). Regarding calving signs, relaxed pelvic ligaments, enlarged or tense udder, and viscous, bloody vaginal discharge are the most frequently reported signs during this stage (Proudfoot et al 2013). However, relaxed pelvic ligaments and suddenly enlarged udders may occur before parturition, or during the first and second stage as well (Noakes 2001). In general, the duration, frequency and amplitude of myometrial contractions increase and become more regular approximately $12 \mathrm{~h}$ before the onset of the second stage (Mainau and Manteca 2011). Finally, the first stage ends with the full dilatation of the cervix and the appearance of the amniotic sac outside the vulva.

The second stage or expulsion phase is characterised by the onset of rhythmic abdominal contractions, the dilation of the birth canal through the allantoic and amniotic sacs, and the progress of the calf through the birth canal. As parturition advances, the distension of the maternal birth canal causes great increases in the release of oxytocin from the posterior pituitary and this, in turn, accentuates the myometrial contractions (Noakes 2001). Schuenemann et al (2011) described this stage indicating that the cow adopts a recumbent position as the forces of the uterine and abdominal contractions help to expel the calf and remain in the same position until birth. The amniotic sac appears immediately before or after the onset of abdominal contractions and the calving progress - characterised by the appearance of the feet of the calf outside the vulva, followed by the nose and head (front presentation) or by the tail and pelvis of the calf (posterior presentation) - is evident every 15-20 min. As cows progress through the second stage of parturition, abdominal contractions are more frequent (between 3 and 9 abdominal contractions every $3 \mathrm{~min}$ ). In cows experiencing normal eutocic calving, the mean time of the second stage has been reported to last between 60 and $110 \mathrm{~min}$ (60 min, Schuenemann et al 2011; 60 to 90 min, Proudfoot et al 2013; 110 min, Campler et al 2015). Also, several studies have reported that in primiparous cows the duration of the second stage is longer compared with multiparous cows (Meyer et al 2001, Noakes 2001, Schuenemann et al 2011). The longer duration of the expulsion phase has also been related to problems in the dam and its offspring (Mee 2004, Gundelach et al 2009). The second stage ends with the delivery of the calf or calves (Schuenemann et al 2011).

The third stage or expulsion of the placenta covers the period from birth until the expulsion of the fetal membranes (Noakes 2001), which normally should occur within the first 12-24 h after birth in both primiparous and multiparous cows (Schuenemann et al 2011). Finally, myometrial contractions persist, decreasing in amplitude but becoming more frequent and less regular in duration (Mainau and Manteca 2011).

\section{MATERNAL BEHAVIOUR IN DAIRY COWS}

In cattle, "maternal behaviour" is commonly used to describe the suite of behaviours expressed by the dam prior and after parturition that facilitate offspring survival and performance (Dwyer 2008, Chenoweth et al 2014). Activation of maternal behaviour is mediated by coordinated hormonal, neural and neuroendocrinal responses, in which hormones such as oestradiol, progesterone, prolactin, and oxytocin play a central role (Bridges 1984, Rosenblatt et al 1988). Furthermore, the expression of maternal behaviour is regulated by sensory stimuli (Rørvang et al $2018^{a}$ ) and experiential events over the female's lifetime (Bridges 2015).

Shortly before parturition, cows seek to isolate as a function of separating or hiding from other herd members and, therefore, give birth in a calm place (Lidfors et al 1994). Once the calf is born, cows invest most of their time licking the calf, a behaviour that stimulates the calf to stand, suckle, decrease heat loss and facilitate the establishment of the mother-offspring bond (von Keyserlingk and Weary 2007). Moreover, it has been shown that the expression of licking behaviour reduces the heart rate in the receiver cow (Laister et al 2011), suggesting a role in alleviating discomfort. Several studies report that older cows licked their newborn calves sooner compared with first parity cows (Le Niendre 1989, Jensen 2012, Campler 
et al 2015), indicating that maternal experience is an important factor for cows' motivation to attend to their offspring and depends on parity number. Around $4 \mathrm{~h}$ after parturition, cows ingest the placenta and the amniotic fluids. It was proposed that placentophagia would have several functions, such as protection against predators, nutrient supply, immunological role, and accentuation of the hypoalgesia (Mainau and Manteca 2011). The latter might be caused by the presence of the placental opioid-enhancing factor, a molecule that potentiates the antinociception in the dam without disrupting the maternal behaviour. In cows, this analgesic effect was observed after the ingestion of amniotic fluids but not placenta (Pinheiro Machado et al 1997). Von Keyserlingk and Weary (2007) and more recently Rørvang et al (2018a), provide comprehensive reviews of the cattle maternal behaviour literature.

\section{CHANGES IN THE BEHAVIOUR OF DAIRY COWS TO PREDICT CALVING TIME}

In cattle, the first stage of parturition is marked by changes in feeding, rumination and lying behaviour. Also, tail raising, turning the head toward the abdomen, sniffing or licking the ground, stepping and an increased amount of time spent in lateral recumbency have been described as signs of imminent calving. It was suggested that these behavioural changes may be used to predict the onset and completion of this stage of parturition in cattle. Table 1 provides a summary of key behavioural changes observed before the onset of calving in indoor and pasture dairy systems. Next, we will discuss changes in the feeding, rumination and lying behaviour, as well as changes in activity and other behaviours observed prior and during the time of parturition, and how changes in these behaviours can be predictors of calving time in dairy cattle.

\section{FEEDING BEHAVIOUR}

Changes in dry matter intake (DMI) and feeding time on the day of calving have been well documented in dairy cows housed within intensive (indoor) group-housed systems (e.g., freestalls barns, compost barns). It has been reported that cows decreased their DMI by approximately $30 \%$ on the day of calving (Huzzey et al 2007, Proudfoot et al 2009, Schirmann et al 2013) compared to the previous day. This decrease occurred from $24 \mathrm{~h}$ to $6 \mathrm{~h}$ before parturition (Table 1). Time spent at the feed bunk on the day of calving follows a similar pattern as DMI (Huzzey et al 2007, Schirmann et al 2013, Büchel and Sundrum 2014), however, with a larger variation between individual cows (Miedema et al 2011 a, Jensen 2012).

Reduction in DMI and feeding time a few hours before calving may be due to a shift in the motivational priorities of the cow, as hypothesized by Proudfoot et al (2009), or due to pain and discomfort associated with the onset of parturition (Huzzey et al 2007). More recently, Neave et al (2017) reported that primiparous dairy cows consumed less feed than multiparous cows during the days around calving $(\mathrm{d}-1$ to $\mathrm{d}+1)$. Additionally, primiparous cows spent more time at the feed bin and were more often replaced (i.e., cases in which a cow replaced another cow by physically making contact and taking her place at the feed bin) than multiparous cows in competitive interactions, reducing their ability to access the feed. This finding suggests that primiparous cows may shift their feeding times, visiting the feed bin when occupancy is lower, and thus avoiding competition with multiparous animals. Further research is necessary to understand how competitive interactions differentially affect the feeding behaviour of primiparous and multiparous animals as calving approaches.

Automated systems for measuring feed intake and feeding behaviour are more applicable to confinement housing systems where cows a receive total mixed ration, and thus it is not surprising that the majority of research has been conducted on cows housed in these types of systems. Feeding behaviour monitors are primarily used in research settings (DeVries et al 2003, Chapinal et al 2007), but commercially available feeding behaviour quantification methods have recently been developed and evaluated (Bikker et al 2014, Borchers et al 2016). Feeding behaviour monitoring is more challenging in grazing systems since visually observing grazing behaviour is time-consuming and open to the interpretation of the observer. Although there is some equipment available to identify grazing activity such as leg switch movement, jaw movement (Umemura et al 2009) and biting and chewing sounds (Laca and Wallis DeVries 2000), with additional information regarding bite mass and intake rate (Rutter et al 1997), most of these techniques are expensive and labour intensive. Delagarde and Lamberton (2015) using affordable sensor equipment (a portable accelerometer that records physical activity level) in their study and concluded that this type of technology is indeed a useful tool for the continuous automatic recording of grazing behaviour in dairy cows at pasture. To our knowledge, there are no electronic systems commercially available that will allow for detailed recording of the feeding behaviour of grazing cows, especially at calving time.

\section{RUMINATION BEHAVIOUR}

Changes in rumination behaviour have been evaluated as a signal of impending calving for cows housed in confinement (Soriani et al 2012, Schirmann et al 2013, Calamari et al 2014, Pahl et al 2014, Büchel and Sundrum 2014, Ouellet et al 2016, Borchers et al 2017). Soriani et al (2012) observed that rumination time declined progressively in the week before parturition, moreover, on the day of calving it decreased $3 \mathrm{~h}$ compared with the dry period. In concordance, Calamari et al (2014) found 
Table 1. Behavioural changes observed before the onset of calving as reported for housed indoor or pasture dairy cows.

\begin{tabular}{|c|c|c|c|c|}
\hline Behaviour & Behavioural measurement & $\begin{array}{c}\text { Type of housing } \\
\text { system }\end{array}$ & Result & Reference \\
\hline \multirow[t]{7}{*}{ Feeding } & Dry matter intake & Indoor & $\downarrow 24 \mathrm{~h}$ before calving & $\begin{array}{l}\text { Huzzey et al 2007, Proudfoot } \\
\text { et al } 2009\end{array}$ \\
\hline & & & $\downarrow 8 \mathrm{~h}$ before calving & Schirmann et al 2013 \\
\hline & & & $\downarrow 6 \mathrm{~h}$ before calving & Büchel and Sundrum 2014 \\
\hline & & Pasture & Not determined & \\
\hline & Feeding time & Indoor & $\downarrow 24 \mathrm{~h}$ before calving & $\begin{array}{l}\text { Huzzey et al 2007, Proudfoot } \\
\text { et al } 2009\end{array}$ \\
\hline & & & $\downarrow 8 \mathrm{~h}$ before calving & Schirmann et al 2013 \\
\hline & & Pasture & Not determined & \\
\hline \multirow[t]{5}{*}{ Rumination } & Rumination time & Indoor & $\downarrow 24 \mathrm{~h}$ before calving & $\begin{array}{l}\text { Soriani et al 2012, Calamari et al } \\
2014\end{array}$ \\
\hline & & & $\downarrow 8 \mathrm{~h}$ before calving & Borchers et al 2017 \\
\hline & & & $\downarrow 6 \mathrm{~h}$ before calving & $\begin{array}{l}\text { Büchel and Sundrum 2014, } \\
\text { Ouellet et al } 2016\end{array}$ \\
\hline & & & $\downarrow 4 \mathrm{~h}$ before calving & $\begin{array}{l}\text { Schirmann et al 2013, Pahl et al } \\
2014\end{array}$ \\
\hline & & Pasture & $\downarrow 24 \mathrm{~h}$ before calving & Clark et al 2015 \\
\hline \multirow[t]{8}{*}{ Lying } & Lying time & Indoor & $\downarrow 24 \mathrm{~h}$ before calving & $\begin{array}{l}\text { Miedema et al 2011, Jensen } \\
\text { 2012, Titler et al 2015, Ouellet } \\
\text { et al 2016, Black and Krawczel, } \\
2016\end{array}$ \\
\hline & & Pasture & $\downarrow 24 \mathrm{~h}$ before calving & $\begin{array}{l}\text { Black and Krawczel, 2016, Rice } \\
\text { et al 2017, Sepúlveda-Varas et al } \\
\text { 2018, Hendriks et al } 2019\end{array}$ \\
\hline & $\begin{array}{l}\text { Transitions standing/ } \\
\text { lying (lying bouts) }\end{array}$ & Indoor & $\uparrow 4 \mathrm{~h}$ before calving & Jensen 2012 \\
\hline & & & $\uparrow 6 \mathrm{~h}$ before calving & $\begin{array}{l}\text { Miedema et al 2011, Ouellet et al } \\
2016\end{array}$ \\
\hline & & & $\uparrow 12 \mathrm{~h}$ before calving & Titler et al 2015 \\
\hline & & & $\uparrow 24 \mathrm{~h}$ before calving & Black and Krawczel 2016 \\
\hline & & Pasture & $\uparrow 24 \mathrm{~h}$ before calving & $\begin{array}{l}\text { Black and Krawczel 2016, } \\
\text { Sepúlveda-Varas et al 2018, } \\
\text { Hendriks et al } 2019\end{array}$ \\
\hline & & & No difference & Rice et al 2017 \\
\hline \multirow[t]{11}{*}{ Activity } & Number of steps & Indoor & $\uparrow 8 \mathrm{~h}$ before calving & Borches et al 2017, \\
\hline & & & $\uparrow 12 \mathrm{~h}$ before calving & Titler et al 2015 \\
\hline & & & $\uparrow 24 \mathrm{~h}$ before calving & Black and Krawczel, 2016 \\
\hline & & Pasture & $\uparrow 24 \mathrm{~h}$ before calving & $\begin{array}{l}\text { Black and Krawczel, 2016, } \\
\text { Hendriks et al } 2019\end{array}$ \\
\hline & & & No difference & Rice et al 2017 \\
\hline & Walking time & Indoor & $\uparrow 24 \mathrm{~h}$ before calving & Miedema et al 2011 \\
\hline & & Pasture & Not determined & \\
\hline & Index activity & Indoor & $\uparrow 6 \mathrm{~h}$ before calving & Jensen 2012 \\
\hline & & Pasture & Not determined & \\
\hline & Neck activity & Indoor & $\downarrow 18 \mathrm{~h}$ before calving & Borches et al 2017 \\
\hline & & Pasture & No difference & Clark et al 2015 \\
\hline
\end{tabular}

$\uparrow$ increase; $\downarrow$ decrease. 
that the decrease in rumination time on the day of calving amounted to $70 \%$ on average of the value observed during the dry period. Table 1 shows that rumination time declines in the hours before parturition, supporting the hypothesis that rumination time measured on an hourly scale is a useful short-term predictor of calving.

Data on rumination behaviour of grazing dairy cows affected by the onset of calving is limited and the few available studies show results similar to those reported in dairy cattle in group-housed systems. In both confinement (Ouellet et al 2016) and pasture-based systems (Clark et al 2015), pregnant dairy cows ruminate less during morning and afternoon hours than in the evening and night in the days before parturition, which is in line with the diurnal normal rumination pattern of cows (Gregorini et al 2012). These results suggest that the reduction in rumination time during the period before calving might be independent of the type of production system (indoor versus pasture). Further investigations are needed to quantify the behavioural differences within a few hours before calving since they would be useful to identify predictors of the onset of calving in grazing cows.

Changes in rumination time at calving might be affected by parity, however, the literature on this topic is scarce. It was reported that primiparous Italian-Friesian dairy cows housed in a freestall barn spent less time ruminating than multiparous cows in the days before calving and at calving time, being this difference particularly pronounced in the week after parturition (Soriani et al 2012). These findings suggest that first lactation cows have more difficulties to cope with calving and the onset of lactation. Daily rumination time differs substantially between housed (Schirmann et al 2012) and pasture-based grazing animals (Gregorini et al 2012). Thus, future work should examine how rumination behaviour is affected by parity under pasture-based conditions.

In recent years, technology that allows rumination time to be easily quantified has become available (Clark et al 2015, Ouellet et al 2016, Borchers et al 2017), and their performance for automated calving prediction has been recently reviewed (Saint-Dizier and Chastant-Maillard 2018). Ouellet et al (2016) evaluated the performance of a 3-dimensional accelerometer attached to the ear tag to predict the onset of calving within $24 \mathrm{~h}, 12 \mathrm{~h}$, and $6 \mathrm{~h}$ in housed dairy cows. The study showed that the reduction in rumination time was more accurate to predict calving within $6 \mathrm{~h}$ before parturition than $12 \mathrm{~h}$ or $24 \mathrm{~h}$, however, with lower performance (63\% sensitivity and specificity). Borchers et al (2017), using a collar consisting of an accelerometer and a microphone and applying three machine-learning techniques, found a greater level of sensitivity (72\% to $79 \%$ ) and specificity (80\% to $89 \%)$ to predict calving within $8 \mathrm{~h}$ in housed dairy cows. In pasture-based dairy cows, Clark et al (2015) used a similar collar and achieved $70 \%$ sensitivity and $70 \%$ specificity in predicting the day of calving.

\section{LYING BEHAVIOUR AND ACTIVITY}

Reduction in lying time, more frequent posture changes and increase in walking activity are among others the most frequently reported behaviours in prepartum cows (Rørvang et al 2018 ${ }^{\mathrm{a}}$ ). During the last $24 \mathrm{~h}$ before parturition, cows managed in indoor housed conditions spent less time lying down compared with previous days, showing a greater number of shorter duration lying bouts - transitions between standing and lying - per day (Miedema et al 2011 a , Jensen 2012, Ouellet et al 2016). Similarly, cows on pasture also showed shorter lying times around calving (Rice et al 2017, Sepúlveda-Varas et al 2018, Hendriks et al 2019) (table 1).

An increased frequency of lying bouts has been observed in the $6 \mathrm{~h}$ prior to the onset of parturition (Miedema et al 2011'a, Jensen 2012, Ouellet et al 2016), reflecting the increased degree of restlessness (i.e., characterised by increased frequency of postural changes) (Miedema et al $2011^{\mathrm{a}}$, Jensen 2012) and the growing discomfort of the cow associated with the first stage of parturition (Ouellet et al 2016).

An increase in cow activity as calving approaches has been reported in animals housed in both confinement (Miedema et al 2011a, Jensen 2012, Titler et al 2015, Black and Krawczel 2016, Borches et al 2017) and pasture settings (Black and Krawczel 2016, Hendriks et al 2019). However, comparison between studies is difficult because of the different methodological approaches to defining active behaviour. Miedema et al (2011) used continuous focal observations from video to quantify daily durations of walking and observed that cows walked for longer during the $24 \mathrm{~h}$ prior to calving compared to a 24-hour control period during late pregnancy. Jensen (2012) measured an activity index using an accelerometer attached to the cows' legs and reported that cows were more active the day before calving compared to 2-4 $\mathrm{d}$ before calving and, on an hourly scale, the level of activity increased throughout the $6 \mathrm{~h}$ prior to calving compared with the same time of day in the 3 preceding days. Titler et al (2015) monitored cow activity by counting steps using electronic data loggers and reported an increase in the number of steps within the $12 \mathrm{~h}$ immediately prior to calving. Borchers et al (2017) measured the prepartum activity using two types of devices. Firstly, they used data loggers and showed that the number of steps taken by the animals increased $8 \mathrm{~h}$ before calving, compared with a baseline period. Secondly, neck movements were measured using 3-axis accelerometers and it was observed that the overall neck activity decreased to its lowest value $18 \mathrm{~h}$ before calving, and then increased to its highest value $2 \mathrm{~h}$ before calving. More recently, the work of Hendriks et al (2019) showed an increased activity, measured by the number of steps taken using electronic data loggers, on the day of calving in grazing dairy cows.

Lying behaviour and activity at calving seem to be influenced by the housing system. Black and Krawczel 
(2016) observed that cows lay down more frequently on pasture during the day of calving when compared to freestall conditions, suggesting that cows may find pasture a more comfortable surface for changing lying position compared to the mattresses commonly used in freestall calving pens. On pasture, the time required for grazing requires an increase in walking and, therefore, an increase in daily steps. In prepartum beef cows, it has been proposed that the increase in steps may also be due to cows walking in search for a safe place to calve, seeking isolation from the herd, or pacing due to discomfort (Duncan and Meyer 2019). Thus, step count differences may be detected in dairy cows kept in open grazing areas more readily than cows kept in free stalls barns because of differences in the environmental characteristics. On the contrary, another study found no change in lying bouts and numbers of steps during the days before calving in cows housed in the pasture which, according to the authors, may indicate that the pasture provides an adequate environment for cows to lie down (Rice et al 2017).

Differences in lying time (Miedema et al 2011 , Titler et al 2015), frequency of transitions from lying to standing (Neave et al 2017) and activity (Titler et al 2015, Borchers et al 2017) have been reported between primiparous and multiparous cows in freestall housing conditions. Primiparous cows spent less time lying compared with multiparous cows during the final $24 \mathrm{~h}$ preceding calving $(453 \pm 44$ $\mathrm{min} / \mathrm{d}$ vs. $598 \pm 40 \mathrm{~min} / \mathrm{d}$, respectively; Titler et al 2015) and $2 \mathrm{~h}$ prior to calving (Miedema et al 2011 ${ }^{\mathrm{b}}$ ). Authors speculated that this difference might be related to longer labour time and a higher number of contractions during parturition in primiparous cows (Miedema et al 2011 ${ }^{\mathrm{b}}$, Schuenemann et al 2011). Primiparous cows also lay down more frequently, but for shorter periods, during the week before calving and during the period between the day before and after calving (Neave et al 2017) and became more active compared to multiparous cows in the last 6 $\mathrm{h}$ before the onset of parturition (Borchers et al 2017). It has been hypothesised that these behavioural differences related to parity may reflect an increased discomfort in primiparous cows as parturition approaches.

Relatively few studies looked at differences in lying behaviour of primiparous and multiparous dairy cows at calving in pasture-based systems. It was reported that first parity cows have lower daily lying times and higher frequency of lying bouts than multiparous cows during the first week after calving (Sepúlveda-Varas et al 2014). Moreover, increasing parity was associated with lower step counts during the period immediately before and after calving (Hendriks et al 2019). These findings indicate that parity number affects the frequency of lying behaviour and activity around parturition; thus, parity needs to be considered in the analyses of cow behaviour at calving time.

An advantage of measuring lying behaviour and activity is that the available technology is practical and affordable. Although increasing the number of validating sensors are available at the market which can automatically measure lying behaviour (McGowan et al 2007, Ledgerwood et al 2010, Mattachini et al 2013, Borchers et al 2016) and activity (Champion et al 1997, Robert et al 2009, Bikker et al 2014), few studies have attempted to evaluate the performance of these automated sensors to predict calving events using these measures. Titler et al (2015) used an activity index combining the number of steps, lying bouts, and standing time measured by an electronic data logger that was able to predict parturition with a time interval greater than 4 hours in $76 \%$ of the primiparous and multiparous Holstein cows evaluated in freestall barns. Using the same device, Ouellet et al (2016) evaluated lying time and lying bouts in housed cows (freestalls) to check the accuracy in calving prediction and found that a combination of these variables had a greater level of prediction accuracy within the next $6 \mathrm{~h}$ than considering the next $12 \mathrm{~h}$ and $24 \mathrm{~h}$, but with high rates of false negatives and false positives (58\% sensitivity, $61 \%$ specificity). Similarly, Borchers et al (2017) described calving prediction methods applying three machine-learning techniques to a combination of collected lying behavioural variables (numbers of steps, lying bouts and lying time) during the 14 prepartum days and achieved a sensitivity of $38 \%$ to $75 \%$ and a specificity of $88 \%$ to $91 \%$ in predicting the day of calving in housed dairy cows.

Since there are favourable results presented in the scientific literature on the automated detection of lying behaviours and activity to predict calving in dairy cows under confinement (Saint-Dizier and Chastant-Maillard 2018), future research should investigate whether the changes in daily lying time, lying bouts, or activity around the calving event could be used to predict the timing of calving in grazing cows.

\section{OTHER BEHAVIOURS}

In cattle, tail raising is mentioned as a sign of imminent calving (Owens et al 1985, Lidfors et al 1994, Wehrend et al 2006, Miedema et al 2011 a, Lange et al 2017). The frequency and duration of tail raising increase significantly the day before calving and peaks during the $6 \mathrm{~h}$ prior to parturition (Miedema et al 2011 a). There is a growing consensus that raising the tail is one of the most consistent behavioural changes observed in the hours prior to parturition (Wehrend et al 2006, Miedema et al $2011^{\text {a }}$, Lange et al 2017), making it a potentially useful indicator of calving. To date, several systems for calving prediction including inclinometers and accelerometers that detect tail raising are available (Mee et al 2019), but the performance of these marketed devices under field conditions still lack scientific support (SaintDizier and Chastant-Maillard 2015).

Jensen et al (2012), using continuous observation during the final $12 \mathrm{~h}$ prior to calving, reported that multiparous cows frequently turned their head toward their abdomens, 
behaviour that increased during the final $2 \mathrm{~h}$ prior to calving and typically occurred during contractions. Pain and discomfort associated with abdominal contractions during the second stage of parturition (Mainau and Manteca 2011) likely explain that cows might be turning their head due to pain experienced during contractions as described by Jensen et al (2012), especially during the last hours before calving. On the contrary, Lange et al (2017) used repeated observations lasting $15 \mathrm{~s}$ every hour during the $24 \mathrm{~h}$ period before calving and observed that turning the head toward the abdomen did not occur often and did not increase before parturition in primiparous cows. These contradictory results may be explained by the different observational methods used since this behavioural sign lasts a few seconds and may be better detected during continuous observation rather than during repeated observations.

The literature also reports that cows display other behaviours before parturition such as stepping (Lange et al 2017), sniffing or licking at the ground (Miedema et al $2011^{\mathrm{a}}$ ), and an increased amount of time spent in lateral recumbency (Schuenemann et al 2011). More recently, Lange et al (2017) built mathematical equations including different behaviours recorded via direct observations (i.e. tail raising, stepping, turning the head toward the abdomen, and lying lateral with abdominal contractions) to predict the second stage of parturition in dairy cows. These researchers found that the sensitivity and specificity were 69 and 88\%, respectively, for predicting calving within 12 $\mathrm{h}$ for heifers $(\mathrm{n}=29)$ examined from d 269 until calving and the positive predictive values were between $35 \%$ and $73 \%$ depending on the day of gestation, and concluded that predicting the second stage of calving by direct observation of plausible signs is imprecise and therefore not recommendable.

\section{BEHAVIOURAL CHANGES ASSOCIATED WITH DYSTOCIA}

Dystocia, defined as calving difficulty, can be the result of prolonged spontaneous calving (more than 2 hours in the second stage of parturition; Wehrend et al 2006, Kovács et al 2017) or severe assisted extraction of the calf by the farm staff (Mee 2004). Although detecting early behavioural changes associated with dystocia could serve as a useful tool to improve the handling of cattle experiencing a difficult delivery (Mee 2008), the literature is scarce. The lack of studies on pasture conditions might be likely due to the challenges associated with observing or recording calving events under field conditions.

Proudfoot et al (2009) found that cows with dystocia consumed approximately $2 \mathrm{~kg}$ dry matter less during the $48 \mathrm{~h}$ before calving compared with cows with eutocia (14.3 vs. $16.2 \mathrm{~kg}$, respectively), and this difference increased to $2.6 \mathrm{~kg}$ in the $24 \mathrm{~h}$ before calving ( $8.3 \mathrm{vs} .10 .9 \mathrm{~kg} / \mathrm{d}$ ). Cows with dystocia also reduced their feeding time before calving. The authors speculated that this reduction in feed intake could be due to the disproportion of the calf to dam size since larger calves could reduce the amount of space available in the rumen (Stanley et al 1993), or could be the result of pain associated with a large or malpositioned calf. In contrast, other studies reported that during the 6 to 12 $\mathrm{h}$ period preceding calving (Miedema et al $2011^{\mathrm{b}}$, Barrier et al 2012) or at calving time (Wehrend et al 2006) there are no changes in the feeding behaviour of cows with or without dystocia, most likely because the motivation to consume feed significantly decreases in the last hours prior to calving and, more drastically, at calving time (Huzzey et al 2005, 2007).

Focusing on rumination behaviour, cows with dystocia had lower rumination time than cows with normal calving within $8 \mathrm{~h}$ before parturition $(13.2 \pm 2.0$ and $32.4 \pm 2.3$ $\mathrm{min} / 4 \mathrm{~h}$, respectively), and rumination time remained depressed for a longer period of time in dystocic cows than in eutocic cows (Kovács et al 2017). The fact that rumination activity is influenced by acute stress (Herskin et al 2004) suggest that cows with dystocia may have experienced a higher level of stress as parturition approached.

Changes in lying behaviour were also evaluated as early indicators of dystocia but with contradictory results. While some studies propose that lying frequency (i.e. number of lying or standing bouts) increased during parturition in assisted animals (Metz and Metz 1987), and this difference began during the $24 \mathrm{~h}$ before calving (Proudfoot et al 2009) or only during the final $2 \mathrm{~h}$ before calving (Miedema et al 2011 b), compared to unassisted animals, others reported that the number of transitions from lying to standing and vice versa during the last $6 \mathrm{~h}$ before calving is similar between assisted and unassisted cows (Barrier et al 2012). More consistently, no differences in lying time have been found between cows with dystocia and cows with eutocia in the hours preceding calving (Proudfoot et al 2009, Barrier et al 2012, Miedema et al 2011 b; Barraclough et al 2019).

Cows with dystocia display other behaviours during the hours leading up to calving compared with cows that calve without assistance. For instance, increased duration of tail raising was observed before calving in primiparous and multiparous cows that later experienced dystocia, and this was observed earlier in primiparous cows, from $4 \mathrm{~h}$ before calving, compared with only $2 \mathrm{~h}$ before calving in multiparous cows (Miedema et al 2011 $1^{\mathrm{b}}$ ). Similarly, assisted calving multiparous and primiparous cows raised their tail for a longer period of time compared to non-assisted calving cows during the last $6 \mathrm{~h}$ prior to calving (Barrier et al 2012). The latter study also found that dystocic cows lay in lateral recumbency for longer periods of time than cows calving naturally (Barrier et al 2012). These authors have argued that the expression of these behaviors is likely caused by acute pain experienced during the second stage of parturition when the calf enters the birth canal.

Most of the studies agree that when calving is imminent (over the last $24 \mathrm{~h}$ before calf expulsion), cows with 
dystocia showed an increased restlessness compared to cows with eutocia (Metz and Metz 1987, Wehrend et al 2006, Proudfoot et al 2009, Miedema et al 2011 ${ }^{\text {b }}$, Barrier et al 2012). However, the definition of restlessness varies considerably between authors. Wehrend et al (2006) include behaviours such as rubbing against the wall, discharge of urine and scraping on the floor. Barrier et al (2012) assessed restlessness as being the total count of the bouts of standing, walking and of the changes in the weight distribution of the cow's body while in any lying posture. More often, frequent changes between standing and lying positions (i.e. standing or lying bouts) have been interpreted as signs of restlessness (Metz and Metz 1987, Proudfoot et al 2009, Miedema et al 2011 b), and restlessness is commonly used to indicate discomfort and pain in animals. Indeed, dystocia is associated with high levels of pain (Mainau and Manteca 2011).

The above mentioned reports indicate that changes in the feed intake, feeding and rumination time, lying bouts, as well as tail raising behaviour, seem to be promising in the early detection of cows with a higher risk of dystocia. However, the majority of these studies should be considered preliminary due to the small sample sizes used (between 8 to 12 cows per group). Further research is needed to assess differences among parity, breeds and different housing conditions, including pasture-based systems.

\section{MANAGEMENT PRACTICES AND ENVIRONMENTAL FACTORS AFFECTING BEHAVIOUR AT CALVING}

It is well established that the provision of a comfortable environment around parturition minimises the risk of dystocia and enhances the subsequent health of the cow and calf (Mee 2004). In recent years, there has been an increased interest in housing and management practices to ease the calving process. Next, we discuss behavioural responses to common farm management practices and housing conditions including the time of moving a cow to the calving area, the social environment, and the use of a secluded area to calve. We also review the effects of cow exposure to environmental stressors such as hot and cold weather near to calving time on dairy cow's behaviour, with particular emphasis on pasture-based systems.

\section{TIME OF MOVING A COW TO THE CALVING SITE}

Intensively managed dairy farms, cattle is generally moved to a calving area when calving is imminent, and this decision is often based on their due date and/or calving signs. Mee (2004) recommended moving cows to a calving area within 1 or $2 \mathrm{~d}$ before calving to allow animals to adapt to their new environment, social group, and diet. This management practice may be particularly important in heifers, where such stresses can negatively impact the calving process. Heuwiser et al (1987) reported that cows that were moved into a maternity pen $3 \mathrm{~d}$ before calving had lower blood concentrations of cortisol at calving compared with cows moved close to calving, suggesting a lower stress level in cows that had time to adapt to the new environment of the maternity pen. Additionally, Mee et al (2013) in a case-control study, using 30 dairy Irish herds, found that the herds with cows being transferred to the calving unit within $12 \mathrm{~h}$ before calving had a higher risk of perinatal mortality than herds moving cows 12 to $24 \mathrm{~h}$, or more than 2 days before calving.

To date, only Proudfoot et al (2013) have studied the effect of moving cows from a group pen (bedded pack) to a calving area on the expression of normal calving behaviour, reporting that multiparous cows that were moved to an individual maternity pen closer to the time of calving (late first stage of parturition; moved about $2 \mathrm{~h}$ before calving and showing imminent signs of parturition, such as bloody mucous outside of the vulva and the start of abdominal contractions), experienced lower lying time and shorter lying bouts than cows moved with early signs of calving (early first stage of parturition; moved about $12 \mathrm{~h}$ before calving, showing signs of early first stage of parturition, such as raised tail, engorged, tense and leaky udder, and/or relaxed pelvic ligaments), or before any signs (moved on average $74 \mathrm{~h}$ before calving). These behavioural changes may be related to cows spending more time exploring their new environment to ensure that it is a safe place to give birth.

The timing of movement to a calving area is also a management practice that affects the ease of calving and health outcomes. Proudfoot et al (2013) showed that moving multiparous cows in the advanced first stage of parturition may interrupt and prolong the second stage by approximately $30 \mathrm{~min}$. Also, cows with a longer second stage of parturition had higher inflammation levels (measured using haptoglobin) after calving compared with cows moved earlier. Cows experiencing prolonged labour may also be experiencing additional pain and restless behaviour (Mainau and Manteca 2011), increased need for assistance, and are at increased risk of dystocia (Schuenemann et al 2011, Barrier et al 2012). Similarly, Carrier et al (2006) reported a 2.5 -fold increase in stillbirths in cows that were moved during the late part of the first stage of parturition. These findings suggest that moving a calving cow to an individual pen late in the birth process should be avoided as it represents a stressor capable of altering behaviour and affect their ability to calve normally.

Cows can also be moved too early to the calving area. In a recent study, farmers were asked about the moment when the cows and heifers were brought to the calving area, and an overall $42 \%$ of the producers said they brought their cows at the start of the prepartum period, $3 \mathrm{wk}$ before their due date, while $25 \%$ said they moved their cows when the first signs of calving were detected (Villettaz-Robichaud et al 2016). However, first signs of calving could be anything from first to the second stage of labour (i.e. restlessness and 
udder fill to bloody mucus, amniotic sac, or part of the calf emerging from the vagina). Field observations have also reported that cattle are at risk of developing postpartum health disorders such as ketosis and displaced abomasum and elevated blood non-esterified fatty acid concentrations when they remain in an individual calving pen for longer than $3 \mathrm{~d}$ (Cook and Nordlund 2004). It has been proposed that prolonged isolation may be stressful to cattle, which are naturally gregarious, increasing stress and the risk of disease (Sepúlveda-Varas et al 2013). To our knowledge, this approach has not been tested in dairy cows.

\section{SOCIAL ENVIRONMENT}

In intensive indoor dairy production systems, cows usually calve in individual calving pens or group calving pens, depending on the practices related to calving management of the farm (Cook and Nordlund 2004, Villettaz-Robichaud et al 2016). The use of individual calving pens has been recommended to protect the dam from potential social disturbances during calving and to reduce the risk of mismothering (Edwards 1983, Illmann and Špinka 1993). Edwards (1983) observed that when calving in groups, cows found it more difficult to maintain proximity to their calf and spent less time licking their calves compared with cows that calved alone. Also, approximately half of cows showed interest in an alien calf (a calf born from another cow which was not yet removed) before giving birth themselves. Interestingly, these behaviours did not produce the rejection of the cow's own calf, but on the contrary, could lead to the adoption of the alien calf (Illmann and Špinka 1993).

Larger commercial dairy farms are more likely to use group pens than individual pens (Villettaz-Robichaud et al 2016), which may not be consistent with the choice of the cows. Rørvang et al $\left(2018^{\mathrm{b}}\right)$ examined whether periparturient multiparous dairy cows would voluntarily move into individual calving areas placed in a group calving location (referred to as motivation-based calving facilities). In this study, about half of the cows moved away from the group and calved in an individual calving area (34 of 66), with social factors having an important influence on the chance of a cow using the individual calving area; dominant cows were most likely to use the individual calving areas, whereas the presence of a calf born from another cow reduced the chance of cows calving inside the individual calving area.

In group calving areas, the choice of calving site may be also affected by the site of previous calving. In a study, a group of 10 cows was followed recording the location of the breaking of the amniotic sac as well as the place of birth and found that 9 out of the 10 cows calved within a distance of 1 cow length from where the previous calving took place, suggesting that the cows did not select calving site at random and potentially explained by the presence of amniotic fluid from other cows (Rørvang et al 2017ª).
USE OF A SECLUDED AREA TO CALVE

The use of secluded areas in confinement calving settings has been the subject of considerable interest and revision over the last 5 years (Proudfoot et al 2014 ${ }^{\mathrm{a}, \mathrm{b}}$, Rørvang et al $\left.2017^{\mathrm{b}}, 2018^{\mathrm{a}, \mathrm{b}}\right)$. Proudfoot et al $\left(2014^{\mathrm{a}, \mathrm{b}}\right)$ provided the first evidence that indoor-housed cows preferred a secluded environment to calve, particularly when they were housed individually and there was a high level of activity in the barn during the daytime. Rørvang et al $\left(2017^{\mathrm{b}}\right)$ investigated dairy cows' preference regarding the degree of isolation at calving in an individual pen by offering different types (in terms of height, width or both) and levels of isolation (in terms of percentage coverage, $50 \%$ or $75 \%$ ). Results showed that periparturient dairy cows had no preference for a specific calving pen design or level of isolation. However, cows experiencing a longer calving duration (longer second stage labour) were more likely to give birth in the most isolated individual calving pen $(75 \%$ coverage) compared with those without prolonged labour, possibly explained by an increased level of restlessness and increased discomfort during calving that may have motivated them to seek further seclusion. In a follow-up study, researchers examined whether dairy cows would voluntarily isolate in an individual calving pen placed in a group calving setting were access to individual calving pens was free (with a gate permanently open) or for only one cow at a time (with a gate closed that a cow could push through) (Rørvang et al 2018 ${ }^{\mathrm{b}}$ ). Results showed that $50 \%$ of the cows calved in an individual pen, regardless of the presence of a functional gate in the pen or not. Cows housed with permanently open gates tended to be more likely to calve in the individual calving pens compared to cows housed with functional gates, suggesting that cows in labour and experiencing discomfort or pain, may have perceived the gates as obstacles rather than an advantage for isolating before calving.

Under natural extensive pasture environment, cattle search for secure places to hide at calving to find protection from predators and bond with the calf (Rorvang et al $2018^{\mathrm{b}}$ ). The early work of Lidfors et al (1994) reported that some dairy and beef cows isolated themselves before calving but this behaviour only occurred when suitable conditions were present, such as tall grass or tree cover with appropriate grazing sites nearby. Moreover, most cows made use of a shelter for calving when this was available. However, under an intensive pastoral grazing systems, prepartum group cows are commonly managed on small paddocks sizes (defined grazing areas) that are rotationally grazed in order to provide cows with access to a fresh allocation of pasture (Roche et al 2005); in these systems, the majority of calvings occur within the paddock, where there are fewer opportunities to separate and hide from the herd compared to an extensive, pasture-based system. A recent study evaluated dairy cow's preference for calving environment in group-housed in a 
pasture setting (Edwards 2018). Cows had free access to a covered bedded-pack and to 2.1 ha of pasture subdivided into two different sections: open pasture and pasture with natural forage cover. Results showed that the bedded-pack barn $(39 \%)$ and natural forage cover $(35 \%)$ were most frequently selected for calving, compared with the pasture with no forage cover (26\%). Similarly, a previous study reported that, when given a choice, most dairy cows chose to calve in a straw-covered yard rather than in a pasture paddock without forage cover (Edwards 1983). These results suggest that each cow has its preferences for the environment at calving, and the characteristics of the calving area in pasture-based systems may be of importance for determining whether a cow will use it or not at calving.

Collectively, these findings provide evidence that behavioural studies can contribute to understanding the needs and motivation of the periparturient cow to find a secluded area to give birth under both indoor-housed or pasture conditions and, therefore, may also promote animal welfare. However, more research is needed to better understand calving behaviour associated with the design of calving facilities in terms of size, shape and location of the secluded area.

\section{ENVIRONMENTAL STRESSORS}

In grazing production systems in temperate regions (e.g. Chile, New Zealand, and Ireland), dairy cows are kept on pasture all year round or at least for some part of the year. In these regions, cattle are sometimes exposed to adverse weather conditions particularly during summer and winter (Mee and Boyle 2020). In natural extensive environments, cattle will often have opportunities to find shade or shelter, but shade and shelter may not be available under intensive grazing dairy farming conditions (Webster et al 2015). Research has shown that exposure to inclement weather has negative effects on behaviour but most of the work to date has focused on lactating dairy cows, with little research during the prepartum period or when the process of parturition is imminent. Next, we will describe behavioural changes that may be associated with the exposure to hot and cold weather conditions in temperate regions and discuss the effect of providing shade or shelter during periods of adverse weather on the behaviour of dairy cows housed outdoors.

Hot conditions. Heat stress occurs when an animal's heat load is greater than its capacity to lose heat (Van laer et al 2014). Heat stress in cattle not only depends on air temperature, but on another weather factors as well, such as relative humidity, solar radiation, and air movement. For instance, moderate temperatures may already induce heat stress in conjunction with high humidity and intense solar radiation (e.g., $21^{\circ} \mathrm{C}$ and $75 \%$ humidity) (Van laer et al 2014, Webster et al 2015).
Behavioural coping strategies used by lactating cows to avoid a rise in body temperature include modified feeding (Kendall et al 2006, Karimi et al 2015) and grazing behaviour (Kendall et al 2006) (i.e. shifting feeding/grazing times to cooler periods during the day), increased water intake and time spent around a water source (Muller et al 1994, Schütz et al 2010a), reduced lying time (Tucker et al 2008, Schütz et al 2010 ), decreased activity and movement (West 2003, Schütz et al 2008) and reduced rumination time (Soriani et al 2013). A study that evaluated the effects of heat stress (defined as temperature-humidity index, $\mathrm{THI}>72$, equivalent to $25^{\circ} \mathrm{C}$ at $50 \%$ relative humidity) on behavioural changes in prepartum dairy cows under confinement systems, showed that during the last $10 \mathrm{~d}$ before calving the cows adapt to heat stress through increasing meal size and reducing meal duration, as well as increasing standing times (Karimi et al 2015). Similarly, Paudyal et al (2016) reported that the average rumination time during the days prior to calving $(\mathrm{d}-14$ to $\mathrm{d}-1$ ) in healthy cows was lower in the hot season (monthly average THI $\geq 76$ ) compared to the cool season (monthly average THI $<76 ; 428$ vs. $447 \mathrm{~min} / \mathrm{d}$ ), suggesting that variations in rumination behaviour can be explained by weather conditions.

A growing body of work has shown that the seeking of shade is also an important behaviour coping strategy for pasture lactating cows when exposed to hot summer conditions in temperate climates (Kendall et al 2006, Tucker et al 2008, Schütz et al 2008, 2009, 2010a). The work of Kendall et al (2006) showed that during mild summer conditions (average temperature $25^{\circ} \mathrm{C}$ ) dairy cows preferred to stand, as opposed to lying, in shaded areas probably to maximize their surface area exposed to the environment to regulate body temperature. A study by Schütz et al (2008) found that dairy cows in warm conditions (air temperature $>30^{\circ} \mathrm{C}$ ) chose to stand beneath the shade rather than lying after experiencing $12 \mathrm{~h}$ of lying deprivation. Since dairy cattle are highly motivated to lie down (Jensen et al 2005), the authors suggested the motivation to find shade appeared strong relative to the motivation to undertake other valued behaviours such as resting. A follow-up study showed that cows preferred shade that provided more protection from solar radiation (50 and $99 \%$ blockage versus 25\%) (Schütz et al 2009). In the latter study, the average ambient air temperature was $20^{\circ} \mathrm{C}$ (range: $13-24^{\circ} \mathrm{C}$ ). Similar results were reported by Tucker et al (2008) who found that cows with access to a shade that provided more protection from solar radiation, spent more time using it than cows with access to a shade that provided less protection. In both studies, cows spent more time under the shade on days with higher levels of solar radiation and air temperature. Shade use peaked when solar radiation levels were highest (Tucker et al 2008, Schütz et al 2009). In a complementary study, the effect of the amount of shade was tested using 1 of 3 treatments for $5 \mathrm{~d}$ : access to $2.4 \mathrm{~m}^{2}$ or $9.6 \mathrm{~m}^{2}$ shade/cow, or no shade 
during mild summer (Schütz et al 2010 $)$. Cows that had more access to shade spent more than twice as much time in the shade and engaged in fewer aggressive interactions (defined as the contact between any part of one cow and another that resulted in immediate hoof movement), compared to the moment when less shade was available.

Edwards (2018) evaluated the effect of heat stress on calving location preference in dairy cows housed in pasture, where cows could choose to calve either in a covered bedded-pack barn or in a pasture paddock with natural forage. Results showed that cows were more likely to calve in the pasture when they were not experiencing heat-stressed conditions (defined as THI $>68$, equivalent to $21^{\circ} \mathrm{C}$ at $75 \%$ relative humidity). On the contrary, cows preferred to calve inside the barn during heat-stress conditions due to better protection from solar radiation.

Current research concludes that heat-stressed dairy cows, under pasture-based systems, exhibit behavioural changes that indicate that animal welfare is compromised. Cows showed a high motivation to seek and use shade to reduce the impact of heat, but if the shade is insufficient in terms of space, they will increase aggressive behaviour. Furthermore, shade availability seems to be particularly important at calving, playing a role in determining where cattle chose to calve. However, little is known about the effect of heat stress on calving progress. A better understanding of the effects of shade availability, and other mitigation alternatives, on calving behaviour of dairy cows on pasture is needed.

Cold and wet conditions. In general, cattle are much better adapted to cope with low ambient temperatures than hot ambient environments. However, in temperate regions, exposure to winter weather that combines cold, wind and rain, causes cattle to increase heat losses to the surrounding environment, increasing energy requirements to maintain body temperature (Van laer et al 2014, Webster et al 2015).

Dairy cows usually change their behaviour to adapt to increased energy demand. For example, studies using non-lactating Holstein cows have reported that animals decrease food intake and time spent lying, stand with lowered heads, and adopt postures that might reduce heat loss when exposed to a combination of simulated and natural rain and wind in winter (Tucker et al 2007, mean air temperature $5^{\circ} \mathrm{C}$, wind chill factor $-10^{\circ} \mathrm{C}$; Webster et al 2008 , mean air temperature $3^{\circ} \mathrm{C}$, wind chill factor $-0.3^{\circ} \mathrm{C}$; Schütz et al $2010^{\mathrm{b}}$, mean air temperature $10^{\circ} \mathrm{C}$, wind chill factor $-11^{\circ} \mathrm{C}$ ). Since a high body condition helps insulates cows and to maintain more stable body temperatures, thinner cows changed their behaviour to reduce heat loss to a greater extent than well-conditioned cows under cold and wet conditions (Tucker et al 2007).

Another natural behavioural response of dairy cows to wet and windy conditions is seeking shelter. For example, Schütz et al $\left(2010^{\mathrm{b}}\right)$, exposed non-lactating pregnant dairy cattle to one of four treatments (control, wind, rain, wind and rain) created with fans and sprinklers for $22 \mathrm{~h}$, and assessed their motivation to use the shelter by creating a tradeoff between time spent feeding while exposed to the weather treatments and time spent in the shelter. Results showed that cows used the shelter approximately $50 \%$ of the time but with no difference between weather treatments. Those authors have argued that cows were motivated to use the shelters for other reasons than protection from the weather, possibly as a response to social isolation. This behaviour might be particularly important in the hours prior to calving. To our knowledge, this hypothesis has not been tested in grazing dairy cows under inclement weather.

Research has shown that temporarily managing dairy cows on wet and muddy surfaces has negative effects on lying behaviour (Chen et al 2017, Schütz et al 2018). Chen et al (2017), in a simulated stand-off situation exposed pregnant, nonlactating Holstein cows to three levels of soil moisture: 90 (dry), 74 (muddy), or 67\% (very muddy) dry matter for $5 \mathrm{~d}$ each. Results showed that cows spent less time lying down in muddier conditions (dry, muddy, and very muddy treatments: 13,12 , and $9 \mathrm{~h} / 24 \mathrm{~h}$, respectively), and this response was more marked for heifers than for cows. When cattle chose to lie down on wetter soil, they limited the surface area exposed to their surroundings by tucking their legs beneath their bodies (Chen et al 2017). More recently, Schütz et al (2018) assessed the use and preference of pregnant, nonlactating Holstein cows for different wood chip surface types: clean and dry, dirty (contaminated with manure) and clean and wet. During $5 \mathrm{~d}$ of observation, cows were kept $18 \mathrm{~h}$ on woodchip surface and $6 \mathrm{~h}$ on pasture to allow for daily feed intake. Cows on the wet surface spent the least amount of time lying when restricted to one surface for $18 \mathrm{~h}$ (wet: $21 \%$, dirty: $57 \%$, clean: $64 \%$ ), and spent more time lying when on pasture for $6 \mathrm{~h}$ (wet: $13 \%$, dirty: $4 \%$, clean: $3 \%$ ), a time when ideally they should be grazing. Also, when given a choice, they clearly showed that they will avoid wet and dirty surfaces. This later research also suggests that wet surfaces not only influence the duration of rest but also the quality of rest. Cows on wet woodchips spent less time lying in a lateral position and with their heads supported, indicating reduced cow comfort and quality of rest on this surface (Schütz et al 2018).

Spring calving season predominates in grazing systems and the cows are sometimes moved from pasture to a separate area in periods of wet weather (Shütz et al 2019). For instance, some farms in southern Chile use "sacrifice" paddocks to keep prepartum cows (i.e. $3 \mathrm{wk}$ prior to calving) during late winter and early spring. A "sacrifice" paddock can take the pressure off the rest of the farm by allowing grass cover to build up while vulnerable soils are wet. In these winter paddocks, depending on stocking density and usage, surfaces can become wet and muddy. In a recent study of our own, we followed Holstein dairy cows during the prepartum period (e.g., from $3 \mathrm{wk}$ to $1 \mathrm{wk}$ prior to calving) in the winter Chilean 
season (Cartes et al 2019, mean 24/h air temperature $7^{\circ} \mathrm{C}$, range $=-2$ to $\left.16^{\circ} \mathrm{C}\right)$. Cows were housed in pairs in 6 paddocks with $(n=12)$ and without $(n=12)$ access to a shelter with clean and dry wood chip bedding. Cows spent $60 \%$ of their daily time in the shelters and $75 \%$ of this time they were lying down. Furthermore, cows that had access to shelter during the prepartum period spent more time lying down during the wk 3 (706 min/d vs. 559 $\mathrm{min} / \mathrm{d}$ ) and wk 2 (742 $\mathrm{min} / \mathrm{d}$ vs. $566 \mathrm{~min} / \mathrm{d}$ ) before calving compared to cows without shelter access. Shelter use in the wk prior to calving was similar between treatments. This study suggests that the provision of a protected area to rest during the weeks before calving might be beneficial for cow welfare.

In summary, cows can generally tolerate low air temperatures but they seek shelter in wet, windy and muddy conditions, suggesting that protection from inclement winter weather is important even in temperate regions. Also, newborn calves exposed to cold temperatures $\left(<10^{\circ} \mathrm{C}\right)$, wet, and windy conditions show longer times to stand up than calves born during warm and dry weather (Diesch et al 2004). Therefore, the use of a shelter with dry and clean bedding can mitigate the negative effects of inclement weather and wet and muddy underfoot conditions in pasture-based systems. However, there is a lack of information about the effect of continued exposure to wet and muddy conditions throughout the prepartum period. During that time, lying down and getting up safely and comfortably may be of increasing importance due to the growing fetus, as well as on the day of calving when the cow becomes more restless (Lidfors et al 1994, Campler et al 2014). The potential effect of shelter availability in winter paddocks during the prepartum period on the ease of calving has not yet been investigated.

\section{CONCLUSIONS}

Behavioural changes could be used as predictors of normal birth. However, their use as a predictor of calving requiring assistance is still a challenge. Also, common farm management practices and housing conditions, such as the time of movement to the calving area, group housing or provision of a secluded area to calve can impact the behavioural responses of dairy cows at calving. Nevertheless, there is a lack of information regarding these subjects in grazing dairy cows. Exposure to adverse environmental conditions such as heat during the summer, or cold, wet and mud during winter can also have a negative impact on the behavior of cows housed outdoors, and studies on the behaviour of periparturient cows under such weather conditions are scarce. Further investigations on the effects of management practices and environmental conditions at calving time on cow calving behaviour are needed to better understand the behaviour of parturient cows and obtain information that might help producers to improve the care and management of these animals around calving time.

\section{ACKNOWLEDGEMENTS}

Fabiola Matamala would like to thank the Agencia Nacional de Investigación y Desarrollo (ANID) Chile/ Doctorado Nacional/ 2017N²1170749 that granted her Graduate Scholarship.

\section{REFERENCES}

Barraclough RAC, Shaw DJ, Boyce R, Haskell MJ, Macrae AI. 2020. The behavior of dairy cattle in late gestation, effects of parity and dystocia. J Dairy Sci 103, 714-722.

Barrier AC, Haskell MJ, Macrae AI, Dwyer CM. 2012. Parturition progress and behaviours in dairy cows with calving difficulty. Appl Anim Behav Sci 139, 209-217.

Barrier AC, Haskell MJ, Birch S, Bagnall A, Bell DJ, et al. 2013. The impact of dystocia on dairy calf health, welfare, performance and survival. Vet $J$ 195, 86-90.

Bikker JP, van Laar H, Rump P, Doorenbos J, van Meurs K, et al. 2014. Technical note, evaluation of an ear-attached movement sensor to record cow feeding behavior and activity. J Dairy Sci 97, 2974-2979.

Black RA, Krawczel PD. 2016. A case study of behaviour and performance of confined or pastured cows during the dry period. Animals 6, 2-16.

Borchers MR, Chang YM, Tsai IC, Wadsworth BA, Bewley JM. 2016. A validation of technologies monitoring dairy cow feeding, ruminating, and lying behaviors. J Dairy Sci 99, 7458-7466.

Borchers MR, Chang YM, Proudfoot KL, Wadsworth BA, Stone AE, et al. 2017. Machine-learning-based calving prediction from activity, lying, and ruminating behaviors in dairy cattle. J Dairy Sci 100, 5664-5674.

Boyle LA, Boyle RM, French P. 2008. Welfare and performance of yearling dairy heifers out-wintered on a wood-chip pad or housed indoors on two levels of nutrition. Animal 2, 769-778.

Bridges RS. 1984. A quantitative analysis of the roles of dosage, sequence, and duration of estradiol and progesterone exposure in the regulation of maternal behavior in the rat. Endocrinology 114, 930-940.

Bridges RS. 2015. Neuroendocrine regulation of maternal behavior. Front Neuroendocrinol 36, 178-196.

Büchel S, Sundrum A. 2014. Short communication: Decrease in rumination time as an indicator of the onset of calving. J Dairy Sci 97 , 3120-3127.

Calamari L, Soriani N, Panella G, Petrera F, Minuti A, et al. 2014. Rumination time around calving, An early signal to detect cows at greater risk of disease. J Dairy Sci 97, 3635-3647.

Campler M, Munksgaard L, Jensen MB, Weary DM, von Keyserlingk MAG. 2014. Short communication: Flooring preferences of dairy cows at calving. J Dairy Sci 97, 892-896.

Campler M, Munksgaard L, Jensen MB. 2015. The effect of housing on calving behavior and calf vitality in Holstein and Jersey dairy cows. J Dairy Sci 98, 1797-1804.

Carrier J, Godden S, Fetrow J, Stewart S, Rapnicki P. 2006. Predictors of stillbirth for cows moved to calving pens when calving is imminent. Proceeding of the 39th Ann. Am. Assoc. Bovine Pract., Auburn, AL, USA, Pp 158-159.

Cartes D, Strappini A, Held R, Sepúlveda-Varas P. 2019. Provision of shelter during the prepartum period: Effects on behavior and non-esterified fatty acid concentrations of dairy cows in a pasture-based system. Procceddings of the 2019 American Dairy Science Association, Cincinnati, Ohio, USA, Pp 134.

Champion RA, Rutter SM, Penning PD. 1997. An automatic system to monitor lying, standing and walking behaviour of grazing animals. Appl Anim Behav Sci 54, 291-305.

Chapinal N, Veira DM, Weary DM, von Keyserlingk MAG. 2007. Technical Note, validation of a system for monitoring individual feeding and drinking behavior and intake in group-housed cattle. $J$ Dairy Sci 90, 5732-5736.

Chen JM, Stull CL, Ledgerwood DN, Tucker CB. 2017. Muddy conditions reduce hygiene and lying time in dairy cattle and increase time spent on concrete. J Dairy Sci 100, 2090-2103. 
Chenoweth PJ, Landaeta-Hernández AJ, Flöercke C. 2014. Reproductive and maternal behavior of livestock. In: Grandin T, Deesing MJ (eds). Genetics and the Behavior of Domestic Animals. Academic Press, London, UK, Pp 159-194.

Clark CEF, Lyons NA, Millapan L, Talukder S, Cronin GM, et al. 2015. Rumination and activity levels as predictors of calving for dairy cows. Animal 9, 691-695.

Cook NB, Nordlund KV. 2004. Behavioral needs of the transition cow and considerations for special needs facility design. Vet Clin North Am Food Anim Pract 20, 495-520.

Delagarde R, Lamberton P. 2015. Daily grazing time of dairy cows is recorded accurately using the Lifecorder Plus device. Appl Anim Behav Sci 165, 25-32.

DeVries TJ, von Keyserlingk MAG, Weary DM, Beauchemin KA 2003. Technical note: Validation of a system for monitoring feeding behavior of dairy cows. J Dairy Sci 86, 3571-3574.

Diesch TJ, Mellor DJ, Stafford KJ, Ward RN. 2004. The physiological and physical status of single calves at birth in a dairy herd in New Zealand. $N$ Z Vet J 52, 250-255.

Duncan NB, Meyer AM. 2019. Locomotion behavior changes in peripartum beef cows and heifers. J Anim Sci 97, 509-520.

Duve LR, Weary DM, Halekoh U, Jensen MB. 2012. The effects of social contact and milk allowance on responses to handling, play, and social behavior in young dairy calves. J Dairy Sci 95, 6571-6581.

Dwyer CM. 2008. Individual variation in the expression of maternal behaviour, A review of the neuroendocrine mechanisms in the sheep. J Neuroendocrinol 20, 526-534.

Edwards SA. 1983. The behaviour of dairy cows and their newborn calves in individual or group housing. Appl Anim Ethol 10, 191-198.

Edwards E. 2018. Environmental preferences and behavior of transition dairy cattle kept on pasture at the time of calving. MSc Dissertation, Knoxville University of Tennessee, Tennessee, USA

Gregorini P. 2012. Diurnal grazing pattern: Its physiological basis and strategic management. Anim Prod Sci 52, 416-430.

Gundelach Y, Essmeyer K, Teltscher MK, Hoedemaker M. 2009. Risk factors for perinatal mortality in dairy cattle, Cow and foetal factors, calving process. Theriogenology 71, 901-909.

Hendriks SJ, Phyn CVC, Turner S-A, Mueller KM, Kuhn-Sherlock B, et al. 2019. Lying behavior and activity during the transition period of clinically healthy grazing dairy cows. J Dairy Sci 102, 7371-7384.

Herskin MS, Munksgaard L, Ladewig J. 2004. Effects of acute stressors on nociception, adrenocortical responses and behavior of dairy cows. Physiol Behav 83, 411-420.

Heuwiser W, Hartig U, Offeney F. 1987. Importance of glucocorticoids as measures of stress in cattle in the periparturient period. $J$ Vet Med A 34,178-187.

Huzzey JM, von Keyserlingk MAG, Weary DM. 2005. Changes in feeding, drinking, and standing behavior of dairy cows during the transition period. J Dairy Sci 88, 2454-2461.

Huzzey JM, Veira DM, Weary DM, von Keyserlingk MAG. 2007. Prepartum behavior and dry matter intake identify dairy cows at risk for metritis. J Dairy Sci 90, 3220-3233.

Illmann G, Špinka M. 1993. Maternal behaviour of dairy heifers and sucking of their newborn calves in group housing. Appl Anim Behav Sci 36, 91-98.

Jackson PG. 2004. Handbook of Veterinary Obstetrics. $2^{\text {nd }}$ ed. W.B. Saunders, New York, NY, USA.

Jensen MB, Pedersen LJ, Munksgaard L. 2005. The effect of reward duration on demand functions for rest in dairy heifers and lying requirements as measured by demand functions. Appl Anim Behav Sci $90,207-217$.

Jensen MB. 2012. Behaviour around the time of calving in dairy cows. Appl Anim Behav Sci 139, 195-202.

Karimi MT, Ghorbani GR, Kargar S, Drackley JK. 2015. Late-gestation heat stress abatement on performance and behavior of Holstein dairy cows. J Dairy Sci 98, 6865-6875.

Kendall PE, Nielsen PP, Webster JR, Verkerk GA, Littlejohn RP, et al. 2006. The effects of providing shade to lactating dairy cows in a temperate climate. Livest Sci 103, 148-157.
Kovács L, Kézér FL, Ruff F, Szenci O. 2017. Rumination time and reticuloruminal temperature as possible predictors of dystocia in dairy cows. J Dairy Sci 100, 1568-1579.

Laca EA, Wallis De Vries MF. 2000. Acoustic measurement of intake and grazing behaviour of cattle. Grass Forage Sci 55, 97-104.

Laister S, Stockinger B, Regner A-M, Zenger K, Knierim U, et al. 2011. Social licking in dairy cattle-Effects on heart rate in performers and receivers. Appl Anim Behav Sci 130, 81-90.

Lange K, Fischer-Tenhagen C, Heuwieser W. 2017. Predicting stage 2 of calving in Holstein-Friesian heifers. J Dairy Sci 100, 4847-4856.

Le Neindre P. 1989. Influence of cattle rearing conditions and breed on social relationships of mother and young. Appl Anim Behav Sci 23, 117-127.

Ledgerwood DN, Winckler C, Tucker CB. 2010. Evaluation of data loggers, sampling intervals, and editing techniques for measuring the lying behavior of dairy cattle. J Dairy Sci 93, 5129-5139.

Lidfors LM, Moran D, Jung J, Jensen P. 1994. Behaviour at calving and choice of calving place in cattle kept in different environments. Appl Anim Behav Sci 42, 11-28.

Mainau E, Manteca X. 2011. Pain and discomfort caused by parturition in cows and sows. Appl Anim Behav Sci 135, 241-251.

Mattachini G, Antler A, Riva E, Arbel A, Provolo G. 2013. Automated measurement of lying behavior for monitoring the comfort and welfare of lactating dairy cows. Livest Sci 158, 145-150.

McGowan JE, Burke CR, Jago J. 2007. Validation of a technology for objectively measuring behaviour in dairy cows and its application for oestrous detection. In: Proceedings of the New Zealand Society of Animal Production, Wanaka, New Zealand, Pp 136-142.

Mee JF. 2004. Managing the dairy cow at calving time. Vet Clin North Am - Food Anim Pract 20, 521-546.

Mee JF. 2008. Prevalence and risk factors for dystocia in dairy cattle: A review. Vet $J$ 176, 93-101.

Mee JF, Grant J, Sánchez-Miguel C, Doherty M. 2013. Pre-calving and calving management practices in dairy herds with a history of high or low bovine perinatal mortality. Animals 3, 866-881.

Mee JF, English L, Murphy JP. 2019. Preliminary results from a novel tail-mounted calving sensor in dairy cows. Procceddings of the $9^{\text {th }}$ European Conference on Precision Livestock Farming, Cork, Ireland, Pp 735-737.

Mee JF, Boyle L. 2020. Assessing whether dairy cow welfare is "better" in pasture-based than in confinement-based management systems. $N Z$ Vet $J 0,1-24$

Metz J, Metz JHM. 1987. Behavioural phenomena related to normal and difficult deliveries in dairy cows. Neth J Agric Sci 35, 87-101

Meyer CL, Berger PJ, Koehler KJ, Thompson JR, Sattler CG. 2001. Phenotypic trends in incidence of stillbirth for Holsteins in the United States. J Dairy Sci 84, 515-523.

Miedema HM, Cockram MS, Dwyer CM, Macrae AI. 2011ª . Changes in the behaviour of dairy cows during the $24 \mathrm{~h}$ before normal calving compared with behaviour during late pregnancy. Appl Anim Behav Sci 131, 8-14.

Miedema HM, Cockram MS, Dwyer CM, Macrae AI. 2011 ${ }^{\text {b }}$. Behavioural predictors of the start of normal and dystocic calving in dairy cows and heifers. Appl Anim Behav Sci 132, 14-19.

Muller CJC, Botha JA, Smith WA. 1994. Effect of shade on various parameters of Friesian cows in a Mediterranean climate in South Africa. 1. Feed and water intake, milk production and milk composition. S Afr J Anim Sci 24, 49-55.

Neave HW, Lomb J, von Keyserlingk MAG, Behnam-Shabahang A, Weary DM. 2017. Parity differences in the behavior of transition dairy cows. J Dairy Sci 100, 548-561.

Noakes DE. 2001. Parturition and the care of parturient animals. In: Noakes DE, Parkinson TJ, England GCW, Arthur GH (eds). Arthur's Veterinary Reproduction and Obstetrics. Elsevier Saunders, London, UK, Pp 155-187.

Norman HD, Wright JR, Kuhn MT, Hubbard SM, Cole JB, et al. 2009. Genetic and environmental factors that affect gestation length in dairy cattle. J Dairy Sci 92, 2259-2269.

Ouellet V, Vasseur E, Heuwieser W, Burfeind O, Maldague X, et al. 2016. Evaluation of calving indicators measured by automated 
monitoring devices to predict the onset of calving in Holstein dairy cows. J Dairy Sci 99, 1539-1548.

Owens JL, Edey TN, Bindon BM, Piper LR. 1985. Parturient behaviour and calf survival in a herd selected for twinning. Appl Anim Behav Sci 13, 321-333.

Pahl C, Hartung E, Grothmann A, Mahlkow-Nerge K, Haeussermann A. 2014. Rumination activity of dairy cows in the 24 hours before and after calving. J Dairy Sci 97, 6935-6941.

Paudyal S, Maunsell F, Richeson J, Risco C, Donovan A, et al. 2016. Peripartal rumination dynamics and health status in cows calving in hot and cool seasons. J Dairy Sci 99, 9057-9068.

Pinheiro-Machado FL, Hurnik JF, King GJ. 1997. The effect of amniotic fluid ingestion on the nociception of cows. Physiol Behav $62,1339-1344$.

Proudfoot KL, Huzzey JM, von Keyserlingk MAG. 2009. The effect of dystocia on the dry matter intake and behavior of Holstein cows. $J$ Dairy Sci 92, 4937-4944.

Proudfoot KL, Jensen MB, Heegaard PMH, von Keyserlingk MAG. 2013. Effect of moving dairy cows at different stages of labor on behavior during parturition. J Dairy Sci 96, 1638-1646.

Proudfoot KL, Jensen MB, Weary DM, von Keyserlingk MAG. 2014 . Dairy cows seek isolation at calving and when ill. J Dairy Sci 97, 2731-2739.

Proudfoot KL, Weary DM, von Keyserlingk MAG. 2014 ${ }^{\text {b }}$. Maternal isolation behavior of Holstein dairy cows kept indoors. J Animal Sci $92,277-281$.

Rice CA, Eberhart NL, Krawczel PD. 2017. Prepartum lying behavior of Holstein dairy cows housed on pasture through parturition. Animals 7, 1-9.

Robert B, White BJ, Renter DG, Larson RL. 2009. Evaluation of three-dimensional accelerometers to monitor and classify behavior patterns in cattle. Comput Electron Agric 67, 80-84.

Roche JR, Kolver ES, Kay JK. 2005. Influence of precalving feed allowance on periparturient metabolic and hormonal responses and milk production in grazing dairy cows. J Dairy Sci 88, 677-689.

Rørvang MV, Nielsen BL, Herskin MS, Jensen MB. 2017ª . Short communication: Calving site selection of multiparous, group-housed dairy cows is influenced by site of a previous calving. J Dairy Sci 100, 1467-1471.

Rørvang MV, Herskin MS, Jensen MB. 2017 . Dairy cows with prolonged calving seek additional isolation. J Dairy Sci 100, 2967-2975.

Rørvang MV, Nielsen BL, Herskin MS, Jensen MB, Boyle LA. $2018^{\mathrm{a}}$. Prepartum maternal behavior of domesticated cattle, a comparison with managed, feral, and wild ungulates. Front Vet Sci 5, 1-11.

Rørvang MV, Herskin MS, Jensen MB. 2018 ${ }^{\mathrm{b}}$. The motivation-based calving facility, social and cognitive factors influence isolation seeking behaviour of Holstein dairy cows at calving. PLoS One 13, 1-19.

Rosenblatt JS, Mayer AD, Giordano AL. 1988. Hormonal basis during pregnancy for the onset of maternal behavior in the rat. Psychoneuroendocrinology 13, 29-46.

Rutter SM, Champion RA, Penning PD. 1997. An automatic system to record foraging behaviour in free-ranging ruminants. Appl Anim Behav Sci 54, 185-195.

Saint-Dizier M, Chastant-Maillard S. 2015. Methods and on-farm devices to predict calving time in cattle. Vet J 205, 349-356.

Saint-Dizier M, Chastant-Maillard S. 2018. Potential of connected devices to optimize cattle reproduction. Theriogenology 112, 53-62.

Schirmann K, Chapinal N, Weary DM, Heuwieser W, von Keyserlingk MAG. 2012. Rumination and its relationship to feeding and lying behavior in Holstein dairy cows. J Dairy Sci 95, 3212-3217.

Schirmann K, Chapinal N, Weary DM, Vickers L, von Keyserlingk MAG. 2013. Short communication: Rumination and feeding behavior before and after calving in dairy cows. J Dairy Sci 96, 7088-7092.

Schuenemann GM, Nieto I, Bas S, Galvão KN, Workman J. 2011. Assessment of calving progress and reference times for obstetric intervention during dystocia in Holstein dairy cows. J Dairy Sci 94, 5494-501.

Schütz KE, Cox NR, Matthews LR. 2008. How important is shade to dairy cattle? Choice between shade or lying following different levels of lying deprivation. Appl Anim Behav Sci 114, 307-318.
Schütz KE, Rogers AR, Cox NR, Tucker CB. 2009. Dairy cows prefer shade that offers greater protection against solar radiation in summer, Shade use, behaviour, and body temperature. Appl Anim Behav Sci 116, 28-34.

Schütz KE, Rogers AR, Poulouin YA, Cox NR, Tucker CB. 2010 ${ }^{\mathrm{a}}$. The amount of shade influences the behavior and physiology of dairy cattle. J Dairy Sci 93, 125-133.

Schütz KE, Clark KV, Cox NR, Matthews LR, Tucker CB. 2010 Responses to short-term exposure to simulated rain and wind by dairy cattle , time budgets, shelter use, body temperature and feed intake. Anim Welf 19, 375-383.

Schütz KE, Cave VM, Cox NR, Huddart FJ, Tucker CB. 2018. Effects of 3 surface types on dairy cattle behavior, preference, and hygiene. J Dairy Sci 102, 1530-1541.

Schütz KE, Cave VM, Cox NR, Huddart FJ, Tucker CB. 2019. Effects of 3 surface types on dairy cattle behavior, preference, and hygiene. J Dairy Sci 102, 1530-1541.

Sepúlveda-Varas P, Huzzey JM, Weary DM, von Keyserlingk MAG. 2013. Behaviour, illness and management during the periparturient period in dairy cows. Anim Prod Sci 53, 988-999.

Sepúlveda-Varas P, Weary DM, von Keyserlingk MAG. 2014. Lying behavior and postpartum health status in grazing dairy cows. $J$ Dairy Sci 97, 6334-6343.

Sepúlveda-Varas P, Lomb J, von Keyserlingk MAG, Held R, Bustamante $\mathrm{H}$, et al. 2018. Claw horn lesions in mid-lactation primiparous dairy cows under pasture-based systems, association with behavioral and metabolic changes around calving. J Dairy Sci 101, 9439-9450.

Soriani N, Trevisi E, Calamari L. 2012. Relationships between rumination time, metabolic conditions, and health status in dairy cows during the transition period. J Anim Sci 90, 4544-4554.

Soriani N, Panella G, Calamari L. 2013. Rumination time during the summer season and its relationships with metabolic conditions and milk production. J Dairy Sci 96, 5082-5094

Stanley TA, Cochran RC, Vanzant ES, Harmon DL, Corah LR. 1993. Periparturient changes in intake, ruminal capacity, and digestive characteristics in beef cows consuming alfalfa hay. J Anim Sci 71, 788-795.

Titler M, Maquivar MG, Bas S, Gordon E, Mccullough K, et al. 2015. Prediction of parturition in Holstein dairy cattle using electronic data loggers. J Dairy Sci 98, 5304-5312.

Tucker CB, Rogers AR, Verkerk GA, Kendall PE, Webster JR, et al. 2007. Effects of shelter and body condition on the behaviour and physiology of dairy cattle in winter. Appl Anim Behav Sci. 105, 1-13.

Tucker CB, Rogers AR, Schütz KE. 2008. Effect of solar radiation on dairy cattle behaviour, use of shade and body temperature in a pasture-based system. Appl Anim Behav Sci 109, 141-154.

Umemura K, Wanaka T, Ueno T. 2009. Technical note, Estimation of feed intake while grazing using a wireless system requiring no halter. J Dairy Sci 92, 996-1000.

Van laer E, Moons CPH, Sonck B, Tuyttens FAM. 2014. Importance of outdoor shelter for cattle in temperate climates. Livest Sci 159, 87-101.

Villettaz Robichaud M, de Passillé AM, Pearl DL, LeBlanc SJ, Godden SM, et al. 2016. Calving management practices on Canadian dairy farms, Prevalence of practices. J Dairy Sci 99, 2391-2404.

von Keyserlingk MAG Von, Weary DM. 2007. Maternal behavior in cattle. Horm Behav 52, 106-113.

Webster JR, Stewart M, Rogers AR, Verkerk GA. 2008. Assessment of welfare from physiological and behavioural responses of New Zealand dairy cows exposed to cold and wet conditions. Anim Welf 17, 19-26.

Webster JR, Schütz KE, Sutherland MA, Stewart M, Mellor DJ. 2015. Different animal welfare orientations towards some key research areas of current relevance to pastoral dairy farming in New Zealand. $N Z$ Vet $J 63,31-36$

Wehrend A, Hofmann E, Failing K, Bostedt H. 2006. Behaviour during the first stage of labour in cattle, influence of parity and dystocia. Appl Anim Behav Sci 100, 164-170.

West JW. 2003. Effects of Heat-Stress on Production in Dairy Cattle. $J$ Dairy Sci 86, 2131-2144. 